\title{
Separate Vertical Wirings for the Extra-articular Fractures of the Distal Pole of the Patella
}

\author{
Young Mo Kim, MD, PhD, Jun Young Yang, MD, PhD, Kyung Cheon Kim, MD, PhD, Chan Kang, MD, \\ Yong Bum Joo, MD, Woo Yong Lee, MD and Jung Mo Hwang, MD \\ Department of Orthopedic Surgery, Chungnam National University School of Medicine, Daejeon, Korea
}

Purpose: To evaluate the usefulness of separate vertical wirings for extra-articular fracture of distal pole of patella.

Materials and Methods: We have analyzed the clinical results of 18 cases that underwent separate vertical wirings for extra-articular fracture of distal pole of the patella from March 2005 to March 2010, by using the range of motion and Bostman score. Occurrence of complication was also evaluated. Additionally, by taking simple radiographs, the correlation between the postoperative degree of anterior transposition of bone fragment and the time of bone fusion, preoperative length of bone fragment, and occurrence of comminuted fracture were investigated.

Results: It took an average of 13.8 weeks for radiological bone union after separate vertical wiring fixation. Flexion contracture was an average of 0.8 degrees and further flexion was an average of $127.6^{\circ}$, and Bostman score was an average of 27.5 points (excellent in 12 cases, and good in 6 cases). On the first postoperative year, average flexion contracture was 0.6 degrees and further flexion was an average of $136.3^{\circ}$, which exhibited increased joint motion and recovery to normal range of motion, and Bostman score was an average of 28.7 points (excellent in 16 cases, and good in 2 cases). There was no statistically significant difference between the preoperative bone fragment length and presence of comminution, and degree of anterior transposition of bone fragment after fracture union on simple radiograph $(\mathrm{p}=0.175, \mathrm{p}=0.146)$.

Conclusions: We were able to obtain satisfactory clinical results, while preserving the bone fragment by separate vertical wiring fixation for extraarticular fracture of distal pole of patella. Moreover, the method is easy to perform, which is also considered as a useful surgical method for extraarticular fracture of distal pole of patella.

Key words: Patella, Extra-articular fracture of the distal pole, Separate vertical wirings.

\section{Introduction}

Common surgical treatment options for transverse patellar fractures include cerclage wiring, tension band wiring, Magnuson wiring, screw fixation, modified tension band wiring, and cannulated screw fixation with figure-eight wiring ${ }^{1-11)}$. Unfortunately, extra-articular fractures of the distal pole of the patella

Received April 28, 2011; Revised (1st) June 26, 2011; (2nd) July 15, 2011; Accepted July 18, 2011.

Correspondence to: Yong Bum Joo, MD.

Department of Orthopedic Surgery, Chungnam National University Hospital, 640 Daesa-dong, Jung-gu, Daejeon 301-721, Korea.

Tel: +82-42-280-7352, Fax: +82-42-252-7098

Email: jyb0707@cnuh.co.kr

This is an Open Access article distributed under the terms of the Creative Commons Attribution Non-Commercial License (http://creativecommons.org/licenses/by-nc/3.0/) which permits unrestricted non-commercial use, distribution, and reproduction in any medium, provided the original work is properly cited. are difficult to fix due to small bone fragments and comminution and to reduce and maintain the reduction due to the extension mechanism of the knee $\mathrm{e}^{3,5,6,12)}$. An extra-articular fracture of the distal pole of the patella with large fragments and mild comminution can be managed with one of the above mentioned methods ${ }^{5,13-15)}$, but they are not applicable in a majority of cases. The most common procedure is to attach the patellar tendon to the patella by transosseous pull-out suture after removal of bone fragments ${ }^{12,16)}$. However, this procedure requires a long fixation period and delays rehabilitation, which eventually results in weakness of the quadriceps femoris muscle ${ }^{12)}$. To deal with these problems, in 2003 Yang and Byun ${ }^{12)}$ introduced separate vertical wiring for comminuted fractures of the distal pole of the patella. In this study, we analyzed the clinical and radiological outcomes of separate vertical wiring ${ }^{12)}$ for the treatment of extra-articular fractures of the distal pole of the patella. 


\section{Materials and Methods}

\section{Materials}

Out of the 21 patients (21 cases) who underwent separate vertical wiring $^{12)}$ for extra-articular fracture of the distal pole of the patella at our institution between March 2005 and March 2010, 18 patients with a minimum 1-year follow-up were included in this study. None of the patients had a combined fracture on the ipsilateral side. The exclusion criterion was partial patellectomy due to severe comminution. Amongst the 18 patients, 10 of them were males and 8 were females with a mean age of 47.1 years (range, 19 to 73 years). Eleven patients had comminuted fractures and 7 had simple fractures. The cause of injury was slipping, traffic accident, and sports injury in 9, 7, and 2 cases, respectively. The mean postoperative follow-up period was 29.9 months (range, 12 to 65 months) (Table 1 ).

\section{Surgical Technique and Postoperative Care}

The patella was exposed by an anterior vertical incision and cleaned. After removing hematoma, the torn retinaculum, fracture pattern, and fracture surface were identified. Separate vertical wiring procedure as introduced by Yang and Byun ${ }^{12)}$, was performed in all the cases by using 3 separate vertical wires (Fig. 1). In 4 cases, for vertical wire insertion, three $4.0-\mathrm{mm}$ cannulated screws (cannulated screw, Depuy-Ace, Warsaw, New York, USA) were placed in the proximal bone fragments and then the wires were passed through the tunnel of each screw. This was because we thought based on our experience that the wires could be anteriorly displaced during wire tightening considering that the wire in the proximal patella is located in the cancellous bone that is a relatively weak structure (Fig. 2). Displaced fragments in the anterior cortex of the patella were stabilized with absorbable sutures. The joint stability was evaluated during joint movement exercises and the torn retinaculum was repaired with absorbable sutures. Long-leg cast immobilization was performed for 4 consecutive postoperative weeks. From the 5th postoperative week, joint exercise was started with an increment of $10^{\circ}$ after every week. Immediately postoperatively, partial weight bearing with crutch assistance was initiated. From the 8th postoperative week, full weight bearing was allowed.

Table 1. Details and Demography of the Patients. The Results Are Based on the Grading Scale of Bostman et al. ${ }^{17)}$ at the Latest Follow-Up

\begin{tabular}{|c|c|c|c|c|c|c|c|c|}
\hline Case & Age (y) & Sex & Injury mechanism & Comminution & $\begin{array}{l}\text { Union time } \\
\text { (wk) }\end{array}$ & Knee scoring ${ }^{\text {a) }}$ & Length of fragment & $\begin{array}{c}\text { Length of anterior } \\
\text { displacement }\end{array}$ \\
\hline 1 & 73 & $\mathrm{~F}$ & Slip down & Yes & 16 & Good (21) & 33.0 & 0 \\
\hline 2 & 39 & M & TA & Yes & 12 & Excellent (30) & 22.0 & 0 \\
\hline 3 & 47 & $\mathrm{~F}$ & Slip down & No & 14 & Excellent (30) & 14.0 & 3.3 \\
\hline 4 & 35 & F & TA & Yes & 14 & Excellent (30) & 21.0 & 5.0 \\
\hline 5 & 48 & M & Slip down & No & 15 & Excellent (30) & 22.0 & 5.9 \\
\hline 6 & 55 & M & Slip down & Yes & 12 & Excellent (30) & 17.0 & 0 \\
\hline 7 & 62 & M & Slip down & No & 18 & Excellent (28) & 24.5 & 3.3 \\
\hline 8 & 41 & $\mathrm{~F}$ & TA & No & 13 & Excellent (29) & 15.6 & 3.2 \\
\hline 9 & 51 & $\mathrm{~F}$ & Slip down & Yes & 15 & Excellent (28) & 22.4 & 4.2 \\
\hline 10 & 26 & M & Sports injury & Yes & 10 & Excellent (29) & 14.0 & 0 \\
\hline 11 & 54 & F & Slip down & No & 12 & Excellent (29) & 18.3 & 0 \\
\hline 12 & 56 & M & Slip down & No & 12 & Excellent (29) & 16.2 & 8.7 \\
\hline 13 & 56 & M & $\mathrm{TA}$ & No & 14 & Good (24) & 20.3 & 0 \\
\hline 14 & 42 & $\mathrm{~F}$ & TA & Yes & 16 & Excellent (29) & 20.6 & 3.8 \\
\hline 15 & 66 & F & Slip down & Yes & 18 & Excellent (29) & 23.4 & 0 \\
\hline 16 & 36 & M & TA & Yes & 13 & Excellent (30) & 34.8 & 0 \\
\hline 17 & 19 & M & Sports injury & Yes & 12 & Excellent (30) & 30.3 & 0 \\
\hline 18 & 42 & M & TA & Yes & 12 & Excellent (30) & 23.2 & 4.5 \\
\hline Mean & 47.1 & & & & 13.8 & Excellent (28.7) & 21.8 & 2.32 \\
\hline
\end{tabular}

F: female, M: male, TA: traffic accident.

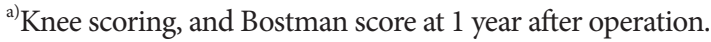



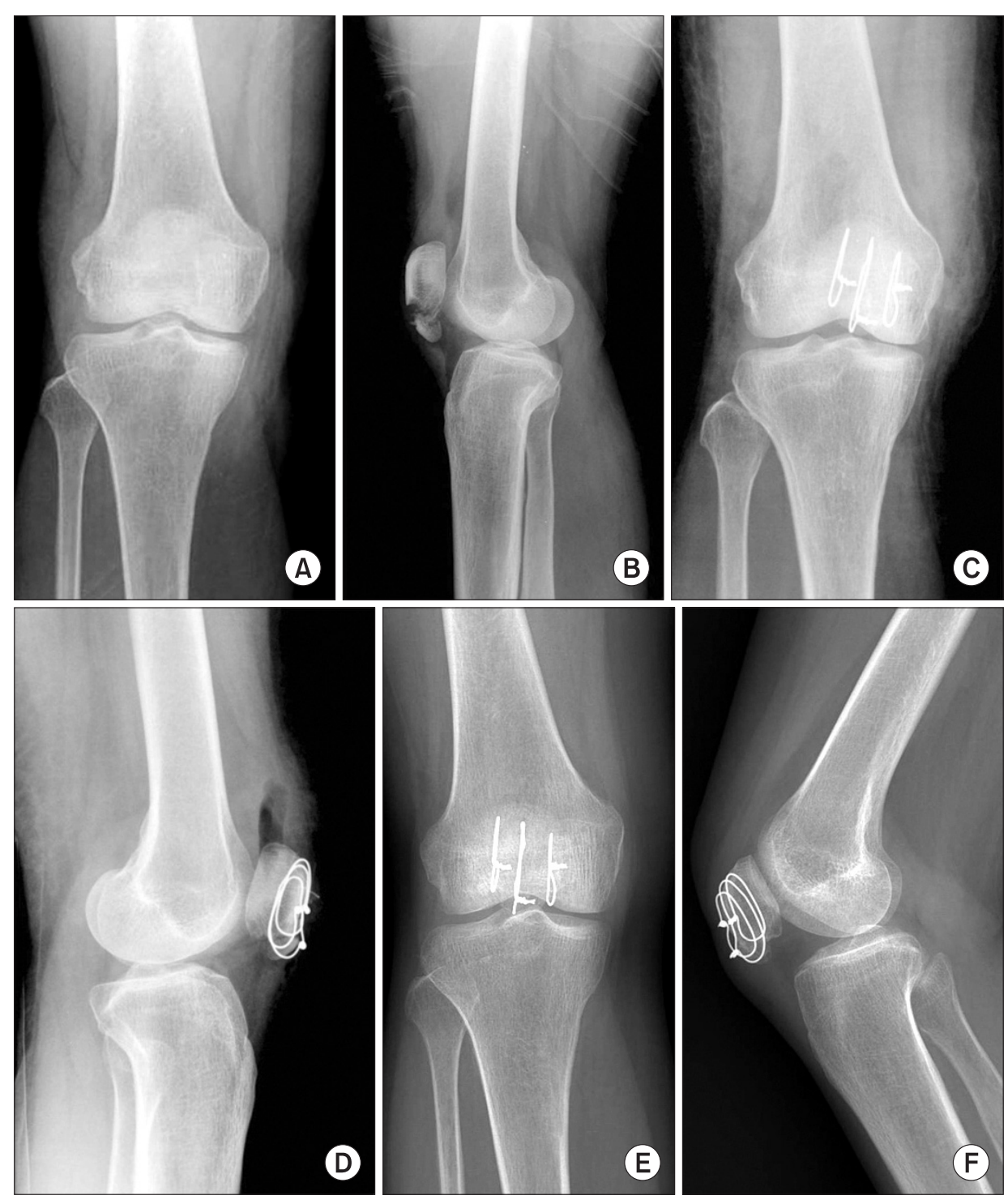

Fig. 1. Radiographs of 47-year-old female patient. (A) anteroposterior and (B) lateral radiographs showing simple, transverse fracture of patellar inferior pole. Postoperative (C) anteroposterior and (D) lateral radiographs showing firm fixation. Postoperative 1 year (E) anteroposterior and $(\mathrm{F})$ lateral radiographs showing united fracture without any complications.

\section{Postoperative Results Assessment}

Clinical results were graded as excellent, good, and unsatisfactory according to the range of motion and Bostman score ${ }^{17)}$ (Table 2), that were evaluated at 6 months and 1 year after surgery (Table 1). For radiological assessment, the relationship between the preoperative bone fragment length and the anterior displacement of the bone fragment after bone union and between the presence of comminution and the anterior displacement of the bone fragment after union were examined on plain radiographs taken preoperatively and during the follow-up. The bone fragment length was measured along the long axis of the fragment on the lateral view. The anterior displacement was measured as the length of a line perpendicular to the tangent line of the displaced point of the original contour of the cortex to the anterior cortical bone of the fragment on lateral plain radiographs taken after

bone union (Fig. 3).

The range of motion, nonunion, avascular necrosis, traumatic arthritis, and hardware failure were examined until the last follow-up. For statistical analysis, Pearson's correlation analysis and paired $t$-test were employed. Measurements on plain radiographs were performed twice, each by 2 authors with an interval of one week. The intra-observer and inter-observer reliability was determined using the Pearson's correlation analysis.

\section{Results}

Radiological union defined as the loss of the fracture line and presence of bony trabecular continuity was achieved 13.8 weeks after surgery on average (range, 10th to 18 th week). At the 6th postoperative month, the mean flexion contracture was $0.8^{\circ}$ 

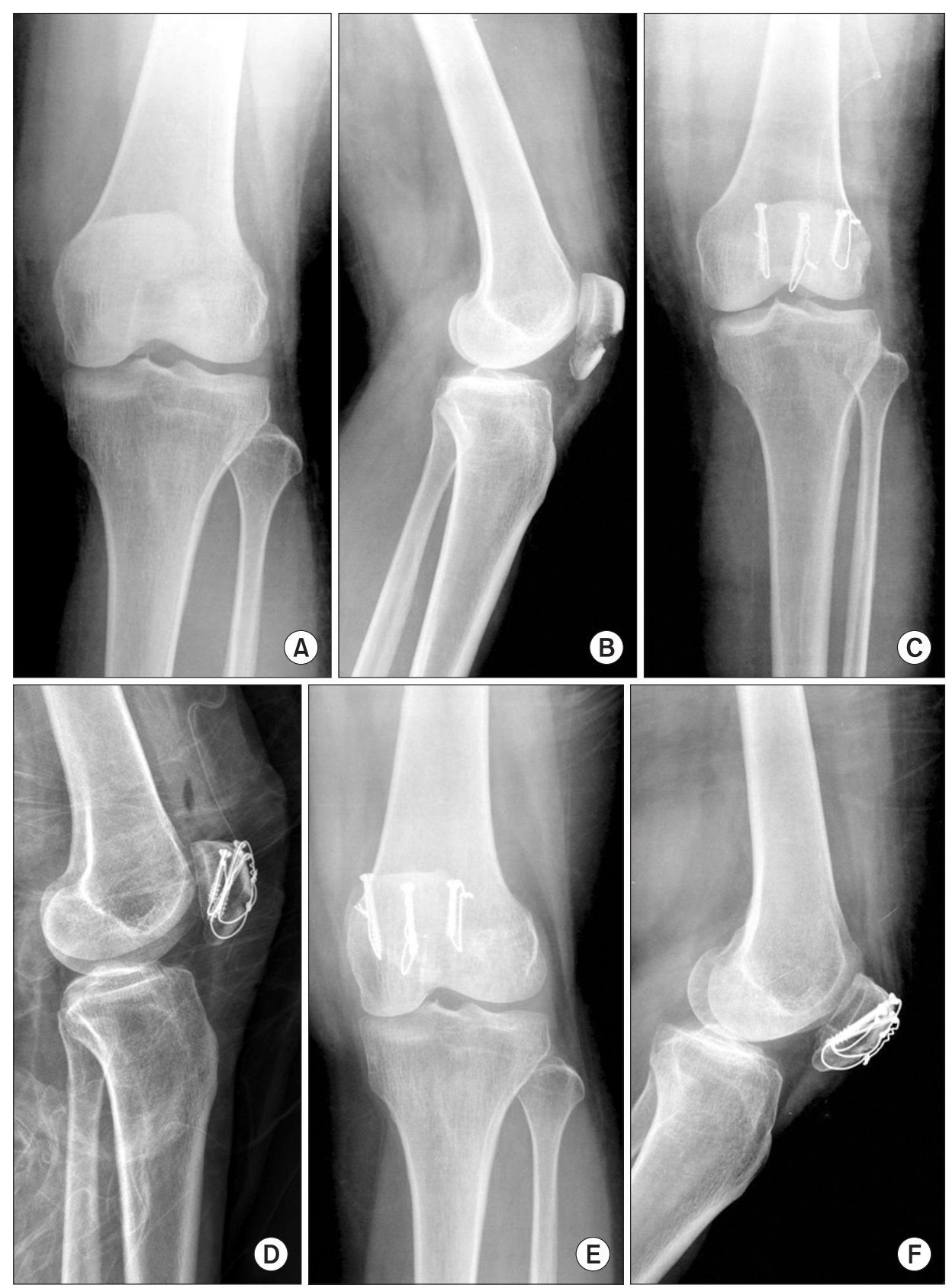

Fig. 2. Radiographs of 54-year-old female patient. (A) Anteroposterior and (B) lateral radiographs showing simple transverse fracture of patellar inferior pole. Postoperative (C) anteroposterior and (D) lateral radiographs showing firm fixation. Postoperative 1 year (E) anteroposterior and (F) lateral radiographs showing united fracture without any complications.

(range, $0^{\circ}$ to $5^{\circ}$ ) and the mean further flexion was $127.6^{\circ}$ (range, $127^{\circ}$ to $140^{\circ}$ ). At the 1st postoperative year, the mean flexion contracture was $0.6^{\circ}$ (range, $0^{\circ}$ to $5^{\circ}$ ) and the mean flexion was $136.3^{\circ}$ (range, $129^{\circ}$ to $140^{\circ}$ ). The mean preoperative bone fragment length was $21.8 \mathrm{~mm}$ (range, 14 to $34.8 \mathrm{~mm}$ ). Bone union occurred with the bone fragment anteriorly displaced in 9 cases (50\%). The mean anterior displacement was 2.32 $\mathrm{mm}$ (range, 0 to $8.7 \mathrm{~mm}$ ). However, no statistical significance was found between the bone fragment length and the anterior displacement $(\mathrm{p}=0.175)$. Comminuted fracture was observed in
11 cases and there was no correlation between the comminution and anterior bone fragment displacement $(\mathrm{p}=0.146)$. Hardware failure, loss of reduction, and nonunion were not observed in any of the cases. The mean Bostman score at the 6th postoperative month was 27.5 points (range, 21 to 30 points) with 12 excellent and 6 good cases and the value at the 1st postoperative year was 28.7 points (range, 21 to 30 ) with 16 excellent and 2 good cases (Table 1). 

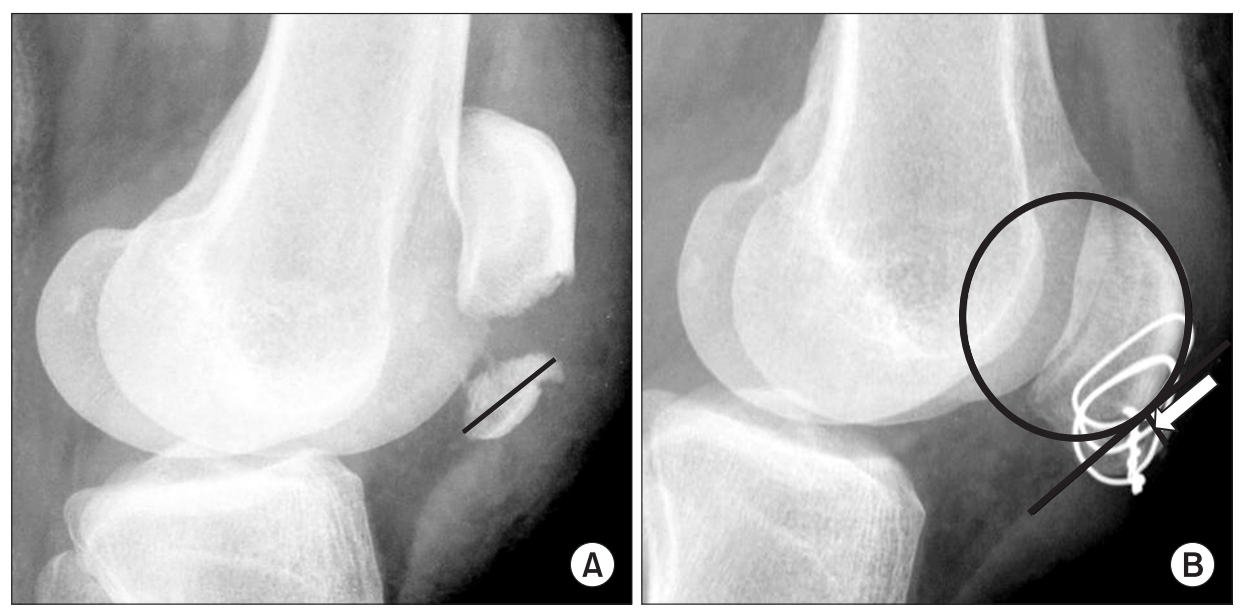

Fig. 3. (A) Lateral radiograph of 41-year-old female patient showing simple, transverse fracture of patellar inferior pole. The length of the fragment in terms of long axis was measured as $15.6 \mathrm{~mm}$. (B) Postoperative 1 year lateral radiograph shows united fracture through anterior displacement. The amount of anterior displacement (whith arrow) was measured as the length of perpendicular line of tangential line from the displaced point of original contour of the cortex. The length was measured to be $3.2 \mathrm{~mm}$.

\section{Discussion}

The patella is a sesamoid bone that is embedded in the tendon of the quadriceps femoris muscle and is essential for knee extension $^{18)}$. Patellar fractures account for $1 \%$ of all the fractures and extra-articular fractures of the distal pole of the patella comprise only $9.3-22.4 \%$ of all the patellar fractures ${ }^{18,19)}$. Studies are limited due to the small number of subjects and there are not enough published reports. Unfortunately, extra-articular fractures of the distal pole of the patella where the patellar tendon is attached are difficult to manage because of small bone fragments and extension mechanism of the knee. Especially, anatomical reduction is demanding and conventional wire fixation or screw fixation is mostly in-effective for stable fixation because of comminution; hence a surgical method should be chosen with care for extra-articular fractures of the distal pole of the patella ${ }^{12,18)}$.

Modified tension band wiring, which is the most common procedure for the treatment of transverse patellar fractures, is not sufficient to achieve firm fixation of extra-articular fractures of the distal pole of the patella, especially comminuted ones: tension band wires may become loose during joint exercises; loss of reduction may occur; joint movement may be restricted due to irritation to soft tissues caused by prominent k-wires; and complications including internal fixation failure caused by $\mathrm{k}$-wire breakage or loosening can also occur ${ }^{2,4,13,20)}$. Transosseous pullout suture technique and wiring procedures including cerclage wiring may cause pain in the anterior knee due to the use of multiple wires for internal fixation and skin irritation during flexion and extension due to wire protrusion ${ }^{12-14,21)}$.

Recently, a variety of studies on new techniques designed to overcome the disadvantages of the conventional methods have been reported ${ }^{12,18)}$. Yang and Byun ${ }^{12)}$ suggested separate vertical wiring for comminuted extra-articular fractures of the distal pole of the patella. In the biomechanical study using cadaver knees, higher fixation strength than the tension-band wiring was reported and the method was more effective for comminuted fractures of the distal patella by using 3 separate wires when compared to the conventional method that transforms extension force into compression force by contouring 2 wires into the shape of 8 . However, considering that in our study, union was achieved with bone fragments anteriorly displaced in $50 \%$ of the cases, separate transverse compression force alone may not be sufficient to provide anatomical reduction. Matejcic et al. ${ }^{18)}$ reported that basket plate osteosynthesis was more effective in terms of pain, mobility, joint movement, and muscular strength in patients with severe comminuted fractures of the distal pole of the patella when compared to partial patellectomy.

The distal pole of the patella is an extra-articular structure that does not articulate with the femur in the patello-femoral joint. Therefore, we thought that excessive correction for exact anatomical reduction or excision of the distal patella that is impossible to be reduced was not necessary. Instead, we believed that it is more important to restore the extension mechanism of the knee by preserving the bone fragment of the distal patella. Separate vertical wiring technique of Yang and Byun ${ }^{12)}$ focuses more on the preservation of the extension mechanism of the knee than on anatomical reduction of the knee. Indeed, anatomical reduction is difficult to obtain with separate vertical wiring, because of the tendency of anterior displacement of the bone fragment in the process of union. We postulated that there would be a correlation between the anterior displacement of bone fragment and the bone fragment length and the presence of comminution, but no statistically significant relationship was found. Therefore, we thought that the anterior displacement was related with the severity of osteoporosis and tension to the bone 
Table 2. Details of the Clinical Grading Scale of Bostman et al. (From Bostman O, et al. Injury 1981;13:196-202, with permission from Elsevier $)^{17)}$

\begin{tabular}{|c|c|}
\hline Variable & Point \\
\hline \multicolumn{2}{|l|}{ Range of movement (ROM) } \\
\hline $\begin{array}{l}\text { Full extension and the } \mathrm{ROM}>120^{\circ} \text { or within } 10^{\circ} \text { of the } \\
\text { normal side }\end{array}$ & 6 \\
\hline Full extension, movement $90^{\circ}$ to $120^{\circ}$ & 3 \\
\hline \multicolumn{2}{|l|}{ Pain } \\
\hline None or minimal on exertion & 6 \\
\hline Moderate on exertion & 3 \\
\hline In daily activity & 0 \\
\hline \multicolumn{2}{|l|}{ Work } \\
\hline Original job & 4 \\
\hline Different job & 2 \\
\hline Cannot work & 0 \\
\hline \multicolumn{2}{|l|}{$\begin{array}{l}\text { Atrophy, difference of circumference of thigh } 10 \mathrm{~cm} \text { proximal } \\
\text { to the patella }\end{array}$} \\
\hline$<12 \mathrm{~mm}$ & 4 \\
\hline 12 to $25 \mathrm{~mm}$ & 2 \\
\hline$>25 \mathrm{~mm}$ & 0 \\
\hline \multicolumn{2}{|l|}{ Assistance in walking } \\
\hline None & 4 \\
\hline Cane part of the time & 2 \\
\hline Cane all the time & 0 \\
\hline \multicolumn{2}{|l|}{ Effusion } \\
\hline None & 2 \\
\hline Reported to be present & 1 \\
\hline Present & 0 \\
\hline \multicolumn{2}{|l|}{ Giving way } \\
\hline None & 2 \\
\hline Sometimes & 1 \\
\hline In daily life & 0 \\
\hline \multicolumn{2}{|l|}{ Stair-climbing } \\
\hline Normal & 2 \\
\hline Disturbing & 1 \\
\hline Disabling & 0 \\
\hline \multicolumn{2}{|l|}{ Total score } \\
\hline Excellent & $28-30$ \\
\hline Good & $20-27$ \\
\hline Unsatisfactory & $<20$ \\
\hline
\end{tabular}

fragments during surgery. However, we did not investigate the patients' bone density and could not identify the exact cause of tension to the wires during surgery.
In the clinical study conducted by Yang and Byun ${ }^{12)}$, the mean Bostman score at the last follow-up was 29.5 points in 29 patients, who underwent separate vertical wiring for the treatment of comminuted fractures of the distal pole of the patella. In the present study, clinical and radiological assessments showed that firm fixation and normal joint movement were achieved at a minimum of 1 year after separate vertical wiring and the Bostman score was excellent with a mean of 28.7 points. Hence, it is apparent that preservation of the knee extension mechanism is more important than restoration of anatomical reduction in the treatment of extra-articular fractures of the distal pole of the patella.

The limitations of this study include that the follow-up period was short and analytic comparisons with other methods were not conducted. We believe that these limitations should be addressed in further studies.

\section{Conclusions}

We believe that separate vertical wiring is a useful technique that is easy to perform and can provide stable fixation and satisfactory clinical outcomes in the treatment ofextra-articular fractures of the distal pole of the patella.

\section{References}

1. Benjamin J, Bried J, Dohm M, McMurtry M. Biomechanical evaluation of various forms of fixation of transverse patellar fractures. J Orthop Trauma. 1987;1:219-22.

2. Berg EE. Open reduction internal fixation of displaced transverse patella fractures with figure-eight wiring through parallel cannulated compression screws. J Orthop Trauma. 1997;11:573-6.

3. Bostrom A. Fracture of the patella. A study of 422 patellar fractures. Acta Orthop Scand Suppl. 1972;143:1-80.

4. Hung LK, Chan KM, Chow YN, Leung PC. Fractured patella: operative treatment using the tension band principle. Injury. 1985;16:343-7.

5. Johnson EE. Fractures of the patella. In: Rockwood CA, Green DP, eds. Fractures in adults. Vol. 2. 4th ed. Philadelphia: Lippincott Williams \& Wilkins; 1996. p195672.

6. Kim ID, Ihn JC, Kim PT, Park BC, Lyu YG, Park IH, Bae CP. A clinical study of the patellar fracture. J Korean Knee Soc. 1991;3:157-63.

7. Levack B, Flannagan JP, Hobbs S. Results of surgical treatment of patellar fractures. J Bone Joint Surg Br. 
1985;67:416-9.

8. Lotke PA, Ecker ML. Transverse fractures of the patella. Clin Orthop Relat Res. 1981;(158):180-4.

9. Nha KW, Kim BJ, Kim JH, Choi YK, Han KS, Suk SY, Chae DJ, Chung PH. Cannulated scredw fixation with figure-eight wiring of displaced transverse patella fractures. J Korean Orthop Assoc. 2001;36:351-4.

10. Weber MJ, Janecki CJ, McLeod P, Nelson CL, Thompson JA. Efficacy of various forms of fixation of transverse fractures of the patella. J Bone Joint Surg Am. 1980;62:215-20.

11. Wilkinson J. Fracture of the patella treated by total excision. A long-term follow-up. J Bone Joint Surg Br. 1977;59:352-4.

12. Yang KH, Byun YS. Separate vertical wiring for the fixation of comminuted fractures of the inferior pole of the patella. J Bone Joint Surg Br. 2003;85:1155-60.

13. Carpenter JE, Kasman RA, Matthews LS. Fractures of the patella. J Bone Joint Surg Am. 1993;75:1550-61.

14. Nerlich M, Weigel B. Patella. In: Ruedi TP, Murphy WM, eds. AO principals of fracture management. 1st ed. Stuttgart and New York: Thieme; 2000. p483-97.
15. Whittle AP. Fractures of lower extremity. In: Canale ST, ed. Campbell's operative orthopaedics. Vol. 3. 9th ed. St Louis: Mosby; 1998. p2042-179.

16. Labitzke R. From "bone suture" to modern osteosynthesis--a chronology. Chirurg. 1995;66:452-8.

17. Bostman O, Kiviluoto O, Nirhamo J. Comminuted displaced fractures of the patella. Injury. 1981;13:196-202.

18. Matejcic A, Puljiz Z, Elabjer E, Bekavac-Beslin M, Ledinsky M. Multifragment fracture of the patellar apex: basket plate osteosynthesis compared with partial patellectomy. Arch Orthop Trauma Surg. 2008;128:403-8.

19. Hughes SC, Stott PM, Hearnden AJ, Ripley LG. A new and effective tension-band braided polyester suture technique for transverse patellar fracture fixation. Injury. 2007;38:212-22.

20. Smith ST, Cramer KE, Karges DE, Watson JT, Moed BR. Early complications in the operative treatment of patella fractures. J Orthop Trauma. 1997;11:183-7.

21. Hung LK, Lee SY, Leung KS, Chan KM, Nicholl LA. Partial patellectomy for patellar fracture: tension band wiring and early mobilization. J Orthop Trauma. 1993;7:252-60. 